\title{
Rancang Bangun Sistem Peringatan Dini Pada Perlintasan Kereta Api Berbasis Sensor Serat Optik dan Transceiver nRF24L01+
}

\author{
Aldo Novaznursyah Costrada*, Harmadi \\ ${ }^{1}$ Jurusan Fisika Universitas Andalas \\ *aldocostrada@gmail.com
}

\begin{abstract}
ABSTRAK
Telah dirancang sistem peringatan dini pada perlintasan kereta api menggunakan sensor serat optik dengan metode ekstrinsik. Sensor serat optik digunakan untuk mengukur frekuensi dan amplitudo getaran rel kereta api dengan memanfaatkan perubahan tegangan keluaran dari fotodetektor OPT101. Data getaran dikirim dari sensor serat optik ke sistem peringatan dini menggunakan Transceiver nRF24L01+. Rancang bangun sistem peringatan dini ini terdiri dari sumber cahaya berupa dioda laser, serat optik FD-620-10, fotodioda OPT 101, Arduino Uno sebagai unit pemrosesan sinyal, buzzer sebagai alarm untuk menghasilkan bunyi peringatan,dan LCD sebagai penampil teks peringatan. Hasil pengujian dan analisis data yang telah dilakukan terhadap jarak optimal antara ujung serat optik dengan rel kereta api yaitu $3 \mathrm{~mm}$. Jarak maksimum dari pengiriman data Transceiver nRF24L01+ adalah $604 \mathrm{~m}$ tanpa penghalang dan $232 \mathrm{~m}$ dengan penghalang. Dalam skala laboratorium, hasil pengukuran frekuensi getaran dengan alat yang dikembangkan dibandingkan dengan function generator, diperoleh kesalahan rata-rata sebesar $0,55 \%$.

Kata kunci: frekuensi, getaran, dioda laser, serat optik
\end{abstract}

\section{ABSTRACT}

The early warning system in the train crossing path using extrinsic method of optical fiber sensor has been designed. Optical fiber sensor was used to measure the frequency and amplitude of the railway track by exploiding the alteration output voltage of OPT101. The vibration data were sent from optical fiber sensor to early warning system using Transceiver nRF24L01+. The design of early warning system consist of a laser diode, fiber optic FD-620-10, OPT photodiode 101, Arduino Uno as unit of signal processing, LCD as a warning text display, and a buzzer as an alarm to yield the warning sound. The result of the testing and data analyzes that has been done toward the optimal distance between the point of the fiber optic and railway track was $3 \mathrm{~mm}$. The maximum distance for sending the data from Transceiver nRF24L01+ was $604 \mathrm{~m}$ in line of sight condition and $232 \mathrm{~m}$ in non line of sight condition. In the laboratorium scale, the result of frequency measuring of the prototype development than the function generator obtained the average error was $0.55 \%$.

Keywords: fiber optic, frequency, laser diode, vibration

\section{PENDAHULUAN}

Kereta Api merupakan sarana yang dapat terhindar dari kemacetan karena memiliki rute sendiri dan memiliki perlintasan sebidang yang merupakan perpotongan antara jalur kereta api dengan jalan raya. Peraturan Menteri Perhubungan Nomor 24 Tahun 2015 tentang Standar Keselamatan Perkeretaapian, pada perlintasan sebidang diperlukan rambu, marka dan alat pemberi isyarat lalu lintas, pintu perlintasan, serta petugas penjaga pintu perlintasan yang dilakukan oleh pegawai operator prasarana perkeretaapian (Menhub RI, 2015). Kecelakaan pada perlintasan kereta api sering terjadi yang disebabkan oleh kelalaian dari pegawai operator perlintasan perkeretaapian (human error) atau terdapat beberapa jalan yang tidak memiliki petugas perlintasan bahkan palang perlintasan rel kereta api.

Sistem peringatan dini dan pengontrolan palang pintu kereta api otomatis yang telah dikembangkan antara lain Pendeteksi Dini Kedatangan Kereta Api Dengan Viborail Menggunakan Metode Pengenalan Akustik Pada Rel (Ishom dkk, 2015). Rancangan ini menggunakan mikrofon pizoelektrik sebagai sensor getaran pada rel kereta api. Penggunaan sensor ini kontak langsung dengan rel kereta api sehingga dapat mengalami kerusakan akibat kenaikan temperatur rel kereta api. Kusriyanto (2017) juga mengembangkan sistem palang pintu perlintasan kereta api otomatis dengan komunikasi wireless berbasis arduino. Rancangan ini menggunakan sensor getaran SW-04 dan sensor inframerah yang pengambilan data dan aplikasinya masih pada miniatur kereta api. 
Berdasarkan penjelasan di atas, maka dibuatlah rancang bangun sistem peringatan dini pada perlintasan kereta api menggunakan serat optik sebagai sensor getaran. Sensor serat optik pada penelitian ini dirancang menggunakan metode ekstrinsik. Serat optik dipilih karena tidak langsung kontak dengan rel kereta api sehingga dapat menghindari kerusakan sensor akibat kenaikan temperatur pada rel kereta api.

\section{METODE}

\subsection{Alat dan Bahan}

Alat yang digunakan dalam perancangan ini meliputi multimeter digital, function generator, obeng, dan tang penjepit. Bahan yang digunakan meliputi serat optik tipe step index multimode FD-620-10, fotodetektor OPT101, dioda laser, LCD I2C, buzzer, dan Transceiver nRF24L01+.

\subsection{Perancangan Perangkat Keras Sensor Getaran}

Perancangan perangkat keras sensor getaran terdiri dari blok sensor getaran, blok pengolah sinyal, blok transmisi (pengirim \& penerima data), dan output. Diagram blok sistem sensor getaran ditunjukkan pada Gambar 1.

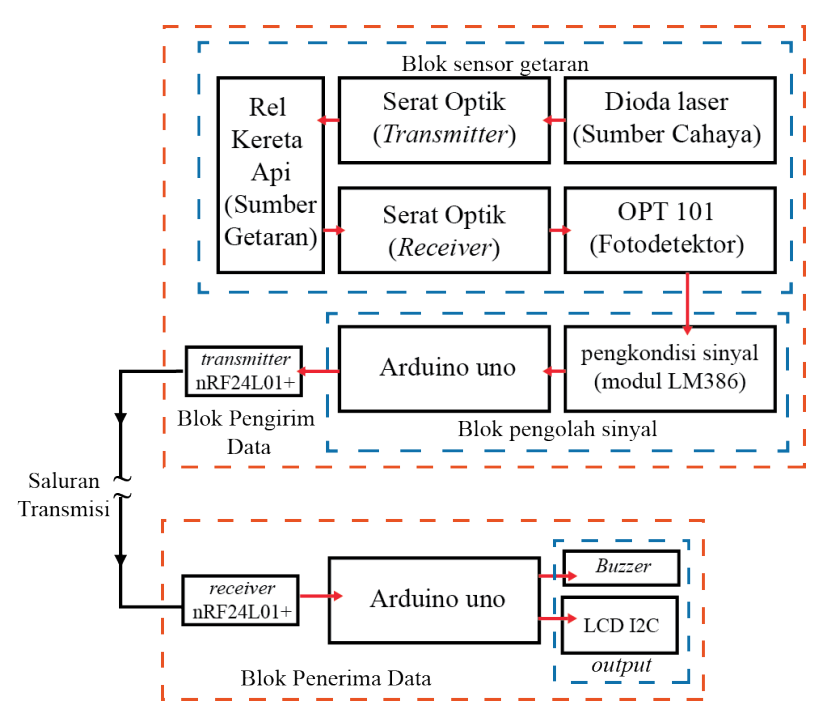

Gambar 1. Diagram blok sistem sensor getaran.

Proses diawali dengan menyusun rangkaian sistem sensor getaran yang dipasang pada rel kereta api. Dioda laser dinyalakan sehingga cahaya dapat merambat pada serat optik transmitter menuju sumber getaran pada rel kereta api. Cahaya yang mengenai rel kereta api dipantulkan ke serat optik receiver dan dipandu menuju fotodetektor OPT101 untuk dikonversi dari besaran fisis berupa intensitas cahaya menjadi besaran listrik berupa tegangan. Tegangan keluaran pada fotodetektor OPT101 diubah ke dalam bentuk amplitudo dan frekuensi. Frekuensi dan amplitudo yang telah terbaca dan diproses oleh Arduino UNO dikirimkan melalui transceiver nRF24L01+ transmitter yang kemudian diterima oleh melalui transceiver nRF24L01+ receiver yang berjarak 500 meter dari transmitter dan diproses pada board arduino UNO. Data frekuensi dan amplitudo membuat buzzer berbunyi dan menampilkan peringatan melalui LCD I2C sebagai peringatan bahwa kereta api melewati perlintasan dengan keterangan yang berbeda.

\subsection{Perancangan Perangkat Lunak Sistem Sensor}

Perancangan perangkat lunak ini bertujuan untuk memproses sinyal masukan dari sensor serat optik ini. Perangkat lunak dibuat dengan aplikasi Arduino IDE menggunakan bahasa $\mathrm{C}$ yang ditanamkan ke mikrokontroller pada Arduino UNO. Diagram alir program pengukuran getaran rel kereta api ditunjukkan pada Gambar 2. 


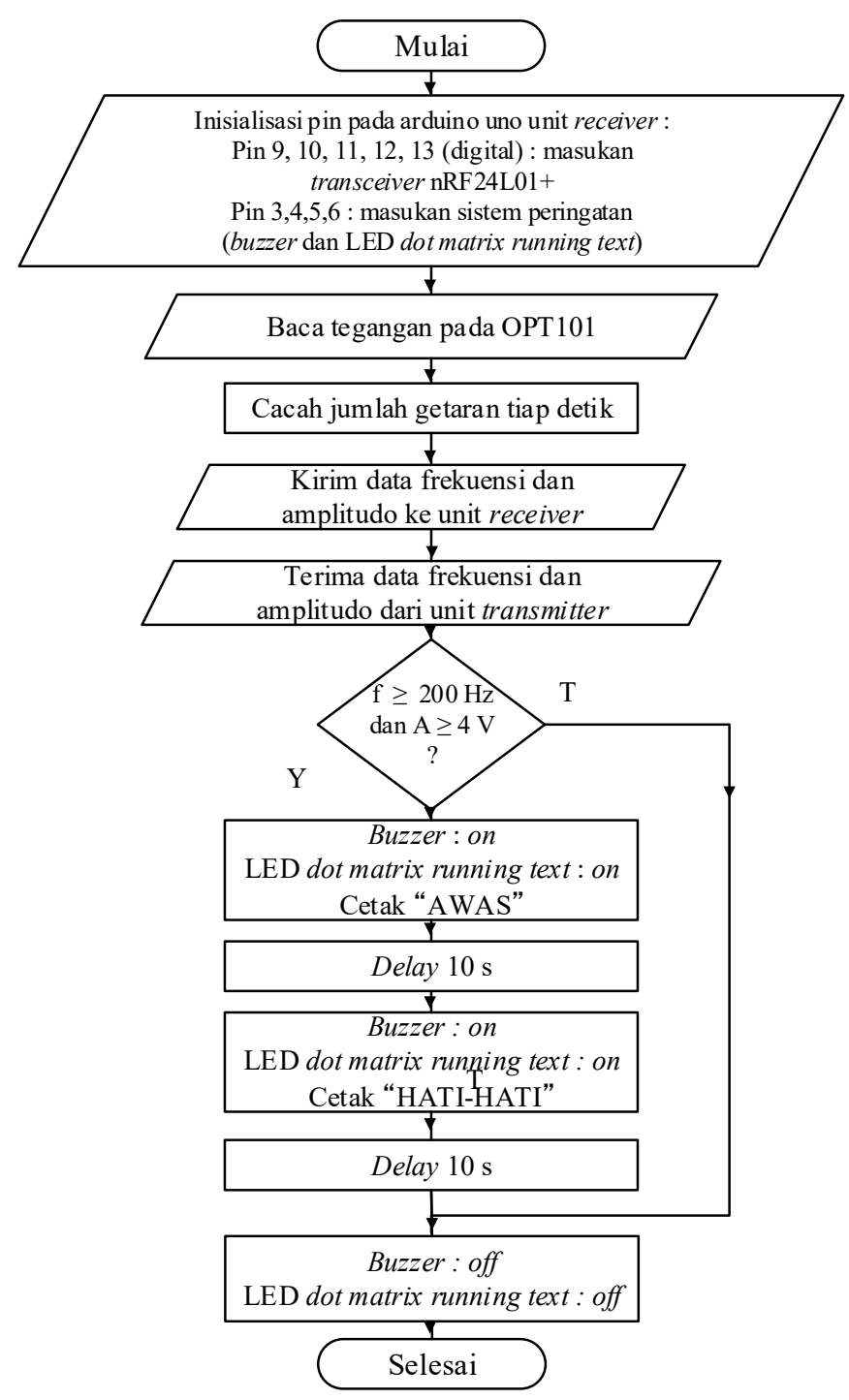

Gambar 2. Diagram alir perangkat lunak sistem peringatan dini berbasis serat optik

Saat frekuensi besar sama dari $200 \mathrm{~Hz}$ dan amplitudo besar sama dari $4 \mathrm{~V}$, bagian sensor getaran akan mengirimkan data tersebut melalui transceiver nRF24L01+. Data yang telah diterima oleh receiver akan mengaktifkan sistem peringatan "AWAS" dan bunyi buzzer selama sepuluh detik, kemudian "HATI-HATI" selama sepuluh detik kemudian buzzer akan dalam keadaan off dan LCD I2C tidak menampilkan peringatan,

\subsection{Karakterisasi Sensor Serat Optik}

Karakterisasi sistem sensor getaran berbasis serat optik meliputi pembuatan sistem sensor menggunakan dioda laser sebagai sumber cahaya, serat optik sebagai medium yang mentransmisikan cahaya yang diterima dari dioda laser, rel kereta api sebagai objek yang akan diukur, dan OPT101 sebagai detektor cahaya laser yang datang dari rel kereta api ke serat optik receiver. Karakterisasi sistem sensor serat optik dilakukan dengan memvariasikan jarak antara ujung serat optik dengan rel kereta api. Data variasi jarak antara ujung serat optik dengan rel kereta api dicatat. Serat optik yang digunakan adalah tipe step index multimode karena terdiri dari dua core yang telah tergandeng dan berfungsi sebagai transmitter dan receiver cahaya. Pemasangan pin dari modul OPT101 ke Arduino UNO yaitu seperti pada Gambar 3. 


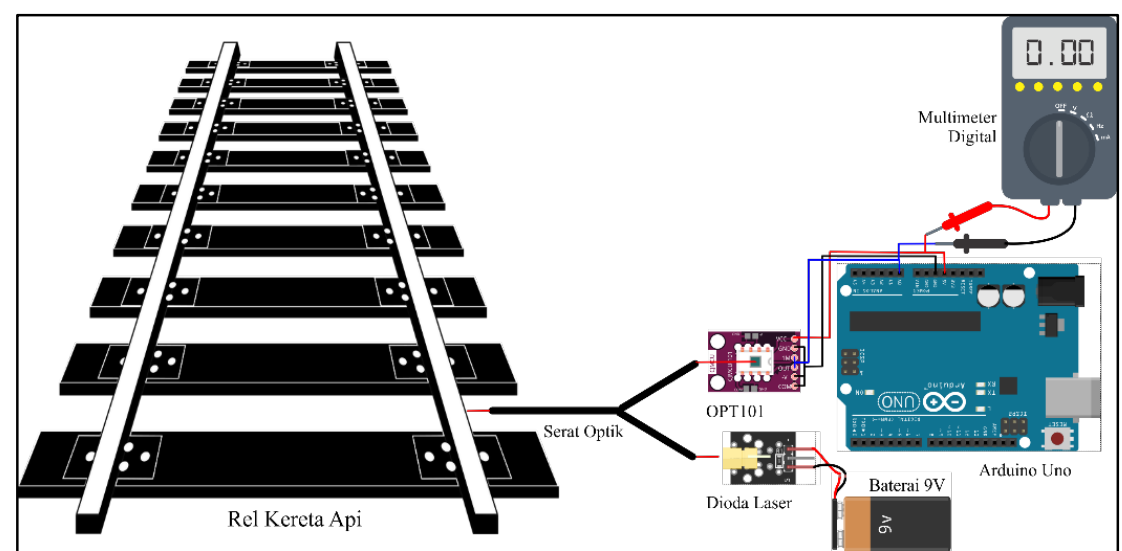

Gambar 3. Skema rangkaian karakterisasi sistem sensor getaran berbasis serat optik

Serat optik dibuat sepanjang 1,6 m untuk menjaga jarak aman dari kereta api yang melintas. Variasi jarak yang diberikan berkisar antara $0 \mathrm{~mm}$ hingga $10 \mathrm{~mm}$ dengan beda sebesar $1 \mathrm{~mm}$. Hasil karakterisasi menentukan jarak paling sensitif untuk melakukan pengukuran amplitudo getaran. Variasi yang dilakukan selanjutnya yaitu variasi antara sensor getaran dengan posisi kedatangan kereta api.

\subsection{Pengujian Sistem Peringatan Dini dan Pengumpulan Data}

Pengujian sistem peringatan dini ini diawali dengan cara mengamati dan mencatat nilai tegangan, amplitudo, dan frekuensi saat kereta api melewati sensor getaran. Variasi data yang dicatat adalah jarak antara sensor dengan sistem peringatan dini melalui pembacaan nilai amplitudo dan frekuensi. Data frekuensi diatas $200 \mathrm{~Hz}$ diproses oleh Arduino UNO menyalakan buzzer dan LCD I2C sebagai tanda peringatan. Bentuk rancangan fisik alat seperti pada Gambar 4.

\section{HASIL DAN DISKUSI}

\subsection{Karakterisasi Sensor Serat Optik}

Karakterisasi sensor dilakukan untuk melihat kemampuan sensor serat optik dalam mendeteksi pergeseran mikro. Karakterisasi dilakukan dengan memberikan variasi jarak antara ujung serat optik dengan rel kereta api. Hal ini menyebabkan tegangan keluaran pada fotodetektor OPT101 yang terbaca pada multimeter digital akan berbeda-beda tergantung pada jarak antara ujung serat optik dengan rel kereta api. Karakterisasi jarak sensor serat optik dimulai dari jarak $1 \mathrm{~mm}-10 \mathrm{~mm}$ dengan beda $1 \mathrm{~mm}$. Tabel 1 menunjukkan hubungan antara tegangan keluaran rata-rata yang dihasilkan OPT101 terhadap variasi jarak ujung serat optik dengan rel kereta api.

Tabel 1 Data karakterisasi jarak antara ujung serat optik dengan rel kereta api

\begin{tabular}{cc}
\hline $\begin{array}{c}\text { Jarak antara ujung } \\
\text { serat optik dengan } \\
\text { rel kereta api }(\mathbf{m m})\end{array}$ & $\begin{array}{c}\text { Tegangan } \\
\text { rata-rata }(\mathbf{V})\end{array}$ \\
\hline 1 & 4,361 \\
2 & 4,356 \\
3 & 4,540 \\
4 & 4,486 \\
5 & 4,389 \\
6 & 4,235 \\
7 & 3,857 \\
8 & 3,788 \\
9 & 3,659 \\
10 & 3,656 \\
\hline
\end{tabular}


Berdasarkan Tabel 1 pada jarak $1-3 \mathrm{~mm}$ nilai tegangan cenderung meningkat, kemudian menurun seiring bertambah jauhnya sensor serat optik terhadap rel kereta api. Tegangan tertinggi dilihat pada tabel yaitu pada jarak $3 \mathrm{~mm}$ dengan tegangan keluaran 4,54 V. hal ini menunjukkan bahwa sudut penerimaan cahaya bagian receiver dari serat optik dengan jarak $3 \mathrm{~mm}$ berada dalam rentang nilai Numerical Aperture (NA) serat optik.

\subsection{Karakterisasi Pengaruh Jarak Sensor Serat Optik dengan Kedatangan Kereta Api}

Karakterisasi dilakukan untuk melihat respon saat kereta api akan melewati sensor serat optik. Karakterisasi dilakukan dengan memberikan variasi jarak antara sensor serat optik dengan kedatangan kereta api. Karakterisasi pengaruh jarak sensor serat optik dengan kedatangan kereta api dimulai dari jarak $0-500 \mathrm{~m}$ dengan beda $50 \mathrm{~m}$. Tabel 2 menunjukkan hubungan antara tegangan keluaran rata-rata yang dihasilkan OPT101 terhadap variasi jarak sensor serat optik dengan kedatangan kereta api.

Tabel 2 Data karakterisasi jarak antara sensor serat optik dengan kedatangan kereta api

\begin{tabular}{cc}
\hline $\begin{array}{c}\text { Jarak antara sensor } \\
\text { serat optik dengan } \\
\text { kedatangan kereta } \\
\text { api }(\mathbf{m})\end{array}$ & $\begin{array}{c}\text { Tegangan } \\
\text { rata-rata }(\mathbf{V})\end{array}$ \\
\hline 0 & 4,540 \\
50 & 3,906 \\
100 & 3,734 \\
150 & 3,499 \\
200 & 3,482 \\
250 & 3,402 \\
300 & 3,403 \\
350 & 3,244 \\
400 & 3,195 \\
450 & 3,153 \\
500 & 3,056 \\
\hline
\end{tabular}

Berdasarkan Tabel 2 terlihat bahwa tegangan keluaran teritinggi berada di jarak $0 \mathrm{~m}$ atau tepat saat kereta api melewati sensor. Nilai tegangan kemudian menurun seiiring dengan bertambahnya jarak antara sensor serat optik dengan kedatangan kereta api. Pada jarak 50-500 $\mathrm{m}$ tegangan keluaran masih dapat terbaca karena getaran yang diakibatkan oleh interaksi antara kereta api dengan rel merambat di sepanjang rel kereta api. Getaran yang merambat pada medium yang padat (dalam hal ini rel kereta api) lebih cepat dibandingkan dengan yang merambat di medium cair ataupun udara.

\subsection{Hasil Pengujian Alat dengan Alat Pembanding}

Pengujian alat dilakukan untuk melihat keakuratan dari alat yang telah dirancang. Pengujian dilakukan dengan cara membandingkan hasil dari sensor serat optik dengan alat pembanding yaitu function generator dan piezoelektrik. Frekuensi yang dihasilkan dari alat pembanding berasal dari function generator yang dihubungkan ke piezzoelektrik. Rentang frekuensi yang diuji yaitu dari $100 \mathrm{~Hz}-500 \mathrm{~Hz}$ yang merujuk rentang frekuensi pada rel kereta api pada penelitian Kouroussis (2014). Hasil pengujian tersebut menghasilkan 5 data frekuensi dengan kesalahan rata-rata frekuensi yaitu $0,55 \%$. Grafik perbandingan nilai frekuensi dari function generator dengan sensor serat optik dapat dilihat pada Gambar . 


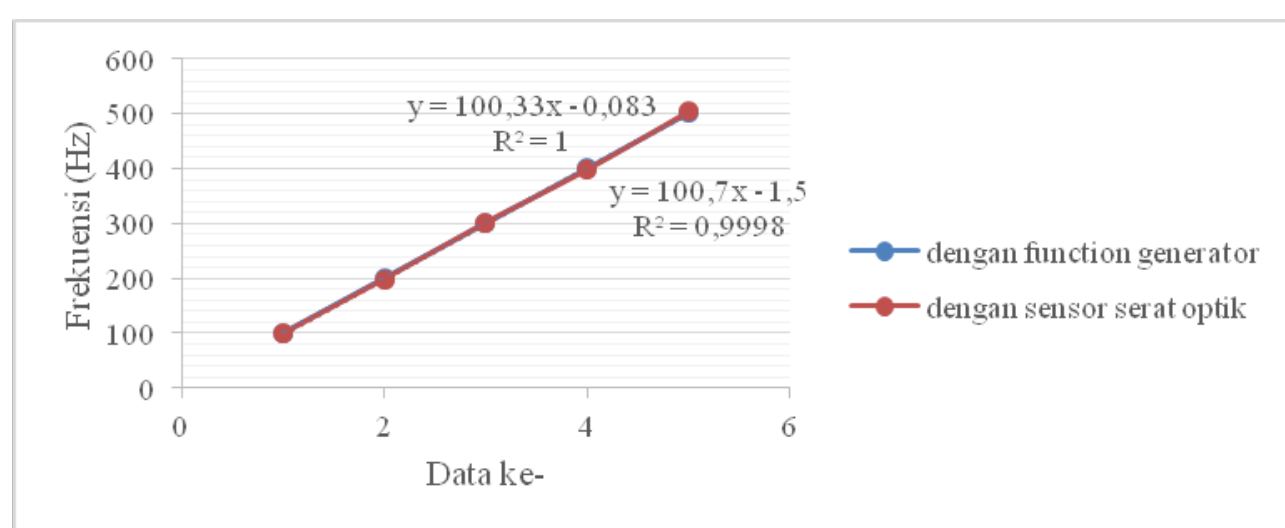

Gambar 4. Grafik hubungan perbandingan frekuensi menggunakan function generator dengan sensor serat optik

\subsection{Hasil Pengujian Alat Secara Keseluruhan Dalam Skala Laboratorium}

Pengujian ini dilakukan menggunakan dua buah batang statif dan penggaris besi yang dimodelkan sebagai rel kereta api. Pengujian skala laboratorium dilakukan karena alat tidak berfungsi pada saat dicoba di lapangan, tetapi berfungsi kembali saat di laboratorium.

Pengujian ini dilihat untuk mengetahui seberapa jauh jarak dari sensor serat optik ke sistem peringatan dini yang dapat mengirimkan data berupa transmitter dan receiver. Jarak terjauh data yang dapat dikirim yaitu sejauh $100 \mathrm{~m}$. Hal ini disebabkan karena area laboratorium yang terdapat banyak penghalang yang mengganggu pengiriman data seperti kondisi geografis kampus dan objek yang dapat membuat gelombang radio dari transceiver nRF24L01+ melemah seperti bangunan di sekitar dan pepohonan. Nilai dari frekuensi dan amplitudo yang dikirim ke unit receiver juga tidak mengalami perubahan. Pada jarak $100 \mathrm{~m}$ peringatan visual dapat tampil di LCD dan peringatan suara dari buzzer dapat berbunyi. Saat lebih dari $100 \mathrm{~m}$ kondisi LCD dan buzzer dalam keadaan off karena tidak menerima data lagi

\section{KESIMPULAN}

Berdasarkan pengujian dan analisis yang telah dibuat, dapat disimpulkan bahwa tegangan optimal dihasilkan pada jarak $3 \mathrm{~mm}$ antara ujung serat optik dengan rel kereta api. Tegangan optimum juga didapatkan pada jarak $0 \mathrm{~m}$ atau tepat saat kereta api melewati sensor serat optik yang jaraknya $500 \mathrm{~m}$ sebelum perlintasan kereta api. Dalam skala laboratorium hasil pengukuran frekuensi getaran alat yang dikembangkan dibandingkan dengan function generator diperoleh kesalahan rata-rata sebesar $0,55 \%$. Sistem peringatan dapat menampilkan peringatan visual dengan LCD I2C dan peringatan bunyi dari buzzer saat frekuensi yang diterima sistem peringatan dini di atas $200 \mathrm{~Hz}$.

\section{UCAPAN TERIMA KASIH}

Dalam terlaksananya penelitian ini banyak pihak yang membantu penulis sehingga dapat menyelesaikannya tepat waktu. Penulis mengucapkan terima kasih kepada Kementrian Riset, Teknologi, dan Pendidikan Tinggi (Kemenristekdikti) Republik Indonesia yang telah menghibahkan bantuan dana penelitian melalui Program Kreativitas Mahasiswa (PKM) tahun 2019.

\section{DAFTAR PUSTAKA}

Kementerian Perhubungan, 2015, Peraturan Direktur Jendral Perhubungan Darat No. SK.770/KA.401/DRJD/2015 tentang Pedoman Teknis Perlintasan Sebidang Antara Jalan dengan Jalur Kereta Api, Jakarta.

Ishom, M., Ziwangga, W.M., Husna, F.A., Andriawan, D., dan Rohman, M.S., "Pendeteksi Dini Kedatangan Kereta Api dengan Viborail Menggunakan Metode Pengenalan Akustik Pada Rel”, Laporan PKM, Politeknik Elektronika Surabaya, 2015.

Kouroussis, G., Connolly, D.P., C., dan Verlinden, O., Int. J. Trail Transp 2, 69-110 (2014).

Kusriyanto, M. dan Wismoyo, N., Teknoin 23, 73-80 (2017). 